\title{
Corrosion Inhibition of Aluminum in Hydrochloric Acid Solution Using Potassium Iodate Inhibitor
}

\author{
A.A. El Maghraby* \\ Chemistry Department, Faculty of Science, Cairo University, Giza, Egypt
}

\begin{abstract}
The inhibition effect of potassium iodate on the corrosion of aluminum in $2 \mathrm{M} \mathrm{HCl}$ has been studied by weight loss, polarization and electrochemical impedance spectroscopy (EIS) measurements. It has been found that $\mathrm{KIO}_{3}$ acts as an excellent inhibitor. Inhibition efficiency with $100 \mathrm{ppm}$ inhibitor was very high. Polarization curves reveal that the used inhibitor is a mixed type inhibitor. The surface adsorption of $\mathrm{KIO}_{3}$ leads to a decrease of double layer capacitance as well as an increase of polarization resistance. The adsorption of the inhibitor on the aluminum surface is in agreement with Temkin adsorption isotherm.
\end{abstract}

Keywords: Aluminum, Corrosion inhibition, $\mathrm{KIO}_{3}, \mathrm{HCl}$.

\section{INTRODUCTION}

It has been reported that the cost due to corrosion in many countries is as high as $5 \%$ of the GNP [1]. This represents a huge amount of money which should have been channeled into the provision of basic social amenities in these countries. In practice corrosion can never be stopped but can be hindered to a reasonable level.

Corrosion of aluminum and its alloys has been a subject of numerous studies due to their high technological value and wide range of industrial applications especially in aerospace and house-hold industries. Aluminum and its alloys, however, are reactive materials and are prone to corrosion. Aluminum relies on the formation of a compact, strongly adherent and continuous passive oxide film is developed on aluminum upon exposure to the atmosphere or aqueous solutions. This is responsible for the corrosion resistance of aluminum in most environments. This surface film is amphoteric and dissolves substantially when the metal is exposed to high concentrations of acids or bases [2]. In addition, aluminum may be used in neutral solutions containing pitting agents such as chloride ions. These solutions cause pitting corrosion. Under these circumstances, corrosion inhibitors should be used because the solubility of the oxide film increases above and below pH4-9 range $[3,4]$ and aluminum exhibits uniform attack.

Aluminum and its alloys are widely used in many industries such as reaction vessels, pipes, machinery and chemical batteries because of their advantages. Hydrochloric acid $(\mathrm{HCl})$ solutions are used for pickling, chemical and electrochemical etching of aluminum. It is very important to add corrosion inhibitors to prevent metal dissolution and minimize acid consumption [5]. Introduction of an oxidizing agent like $\mathrm{KIO}_{3}$ into a corrosive acidic medium can lead to self-passivation of steel. Studies were also reported with $\mathrm{IO}_{3}{ }^{-}$ as an effective inhibitor for corrosion of copper in acidic

*Address correspondence to this author at the Chemistry Department, Faculty of Science, Cairo University, Giza, Egypt;

E-mail:maghraby04@yahoo.com environments. $\mathrm{IO}_{3}{ }^{-}$behaves as an oxidizer at low concentrations and as a passivator at higher concentrations for copper dissolution, with strong adsorption of these ions on copper surface, forming $\mathrm{Cu}\left(\mathrm{IO}_{3}\right)_{2}$ [6]. It has also been found that the presence of $\mathrm{IO}_{3}{ }^{-}$in sulfuric and hydrochloric acids with a concentration higher than the critical one leads to the repair of the flawed regions of the naturally occurring oxide film and oxidation of the active sites on the corroding surfaces of $\mathrm{Ti}$ and Ti-6Al-4V alloy [7]. Based on their adsorption studies, Toraishi et al. observed that $\mathrm{IO}_{3}{ }^{-}$ adsorption onto $\alpha-\mathrm{Fe}_{2} \mathrm{O}_{3}$ occurred from $\mathrm{pH} 4$ to 10 [8]. $\mathrm{KIO}_{3}$ possesses remarkable corrosion inhibition, anti-microbial and oxidizing properties. Recent studies project KI as an effective synergistic co- inhibitor for acidic environments [913]. Also iodide ions are the most absorbable of halide ions on steel. Until now, no research papers have been published on the use of $\mathrm{KIO}_{3}$ as corrosion inhibitor for aluminum in acidic solutions.

The purpose of the present work is to study the inhibitive action of potassium iodate $\left(\mathrm{KIO}_{3}\right)$ on aluminum in $2 \mathrm{M} \mathrm{HCl}$ using chemical (weight loss) and electrochemical methods including Tafel, linear polarization, open circuit potential (OCP) and electrochemical impedance spectroscopy (EIS) measurements. In addition, the adsorption isotherm of the inhibitor will be investigated.

\section{MATERIALS AND METHODOLOGY}

Aluminum sheets of the tube AA1060 and purity $98.8 \%$ were used in this study. Each sheet was $0.14 \mathrm{~cm}$ in thickness was mechanically press- cut into rectangular coupons of dimension $5 \mathrm{~cm} \mathrm{x} 4 \mathrm{~cm}$. The total surface area of the coupon used was $20 \mathrm{~cm}^{2}$. These coupons were used as cut without further polishing. They were however degreased in absolute ethanol, dried in acetone, and stored in moisture- free desiccators prior to use [14]. All reagents used were BDH analytical grade. They were used as sourced without further purification. The used acid solutions were made from $37 \% \mathrm{HCl}$. Appropriate concentrations of acid were prepared by using double-distilled water. An aqueous solution of $2 \mathrm{M}$ $\mathrm{HCl}$ was used as a blank solution. Potassium iodate provided 
by merck, was used as inhibitor. The concentration range of employed inhibitor was $20-200 \mathrm{ppm}$ in $2 \mathrm{M} \mathrm{HCl}$. In each experiment, the cleaned aluminum coupon was weighed $\left(\mathrm{m}_{1}\right)$ and suspended with the aid of glass rod or hook in a beaker containing $100 \mathrm{ml} 2 \mathrm{M}$ acid solution without and with different doses of $\mathrm{KIO}_{3}$ concentrations ranged from 20- 200 $\mathrm{ppm}$. The coupon was then taken out of the test solution after 60 mins, washed in $70 \%$ nitric acid for 2 min to remove the corrosion products using bristle brush, rinsed with distilled water, dried and re- weighed $\left(\mathrm{m}_{2}\right)$. The weight loss was taken as the difference between the weight at a given time and the initial weight of the test coupon. The average weight loss for two determinations is reported in this study. The temperature was adjusted to $30 \pm 0.1{ }^{\circ} \mathrm{C}$ using MEMERT thermostat.

Corrosion rate and inhibition efficiencies were calculated from the following equations $[15,16]$ :

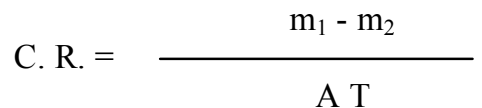

$\mathrm{IE}_{\mathrm{w}} \%=\frac{(\mathrm{C} . \mathrm{R} .)_{\mathrm{o}}-(\mathrm{C} . \mathrm{R} .)}{\text { (C. R. })_{0}} \times 100 \ldots \ldots \ldots \ldots$

where $\mathrm{m}$ is the weight loss in milligram, $\mathrm{A}$ is the total surface area in $\mathrm{cm}^{2}, \mathrm{~T}$ is the time of exposure in minutes, (C. $\mathrm{R})_{0}$ and (C. R.) are the corrosion rates in $\left(\mathrm{mg} \mathrm{cm}^{-2} \mathrm{~min}^{-1}\right)$ without and with different concentrations of $\mathrm{KIO}_{3}$ additives, respectively.

The inhibition efficiency depends on the degree of coverage of the aluminum surface by molecules of the inhibitor and can be expressed as in the following equation [16].

$$
\theta=\frac{(\text { C. R. })_{\mathrm{o}}-(\text { C. R.) }}{\text { (C. R. })_{\mathrm{o}}}
$$

Electrochemical experiments were carried out using potentiostat model 273 / 81 under stirring conditions. In case of Tafel polarization method, scan rate of potential was 5 $\mathrm{mV} / \mathrm{s}$ and potential was scanned in the range of -1150 to $550 \mathrm{mV}$. Three compartment with a saturated calomel reference electrode (SCE) and a platinum auxiliary electrode was used. A sheet cut of $98.8 \%$ pure aluminum of exposed area of $2 \mathrm{~cm}^{2}$ was used for both Tafel and linear polarization studies. The electrode was polished using different grades of emery papers and degreased. For linear polarization studies, the scan rate was $1.66 \times 10^{-4} \mathrm{mV} / \mathrm{s}$ and the polarization resistance $\left(R_{p}\right)$ values were measured in the absence and presence of $100 \mathrm{ppm} \mathrm{KIO}_{3}$ concentration as an optimum dose. Open circuit potential studies were carried out to explore the direction of potential shifting in the presence and absence of inhibitor.

The inhibitor efficiency was evaluated from Tafel polarization curves using the following equation [17].

$I_{\mathrm{p}} \%=\left(1-\frac{\mathrm{i}_{\text {corr }}}{\mathrm{i}_{0 \text { corr }}}\right) \times 100$

where $\mathrm{i}_{0 \text { corr }}$ and $\mathrm{i}_{\text {corr }}$ correspond to uninhibited and inhibited corrosion current densities, respectively.
Electrochemical impedance measurements were carried out in the frequency range of $10 \mathrm{KHZ}-0.1 \mathrm{HZ}$ by applying $5 \mathrm{mV}$ sine wave ac signal. Double layer capacitance $\left(\mathrm{C}_{\mathrm{dl}}\right)$ and charge transfer resistance $\left(R_{t}\right)$ values were calculated from Nyguist plots as described elsewhere [18].

\section{RESULTS AND DISCUSSION}

\subsection{Gravimetric Measurement}

The corrosion rate of aluminum in the absence and presence of potassium iodate at room temperature $\simeq 30^{\circ} \mathrm{C}$ was studied using weight loss technique. The results in Fig. (1) show that $\mathrm{KIO}_{3}$ actually inhibited the corrosion of aluminum in $2 \mathrm{M} \mathrm{HCl}$ solutions. The corrosion rate was found to depend on the concentration of the inhibitor. Increasing the concentration of potassium iodate increases the inhibition efficiency IE\% up to a maximum value of $90 \%$ at nearly $100 \mathrm{ppm}$ inhibitor. No appreciable increase in IE\% was noticed above this concentration. This indicates that the protective effect of $\mathrm{KIO}_{3}$ is not solely due to their reactivity with $\mathrm{HCl}$. The inhibitory action of $\mathrm{KIO}_{3}$ against $\mathrm{Al}$ corrosion can be attributed to the adsorption of its molecules on the $\mathrm{Al}$ surface, which limits the dissolution of the latter by blocking its corrosion sites and hence decreasing the weight loss, with increasing efficiency as the concentration increases.

The percentage inhibition efficiency IE \% and the degree of surface coverage $(\theta)$ were calculated using the following equations:

$$
\begin{aligned}
& \text { IE } \%=\frac{\mathrm{W}_{\mathrm{o}}-\mathrm{W}}{\mathrm{W}_{\mathrm{o}}} \times 100 \\
& \theta=\frac{\mathrm{W}_{\mathrm{o}}-\mathrm{W}}{\mathrm{W}_{\mathrm{o}}}
\end{aligned}
$$

where $\mathrm{W}_{0}$ and $\mathrm{W}$ are the weight loss of the $\mathrm{Al}$ coupon in $2 \mathrm{M}$ $\mathrm{HCl}$ in the absence and presence of $\mathrm{KIO}_{3}$. Fig. (2) shows the effect of immersion time on the performance of inhibitor at its optimum dose $(100 \mathrm{ppm})$. The inhibitor shows good performance up to 1 hour with $87 \%$ inhibition efficiency.

\subsection{Adsorption Considerations}

It is generally assumed that the adsorption of the inhibitor at the metal / solution interface is the first step in the mechanism of inhibition aggressive media. It is also widely acknowledged that adsorption isotherms provide useful insights into the mechanism of corrosion inhibition. The surface coverage, $\theta$, was calculated according to equation (6). Surface coverage values $(\theta)$ for the inhibitor were obtained from the weight loss measurement for various concentrations at $\simeq 30^{\circ} \mathrm{C}$. The best - fitted straight line is obtained for the plot of surface coverage $(\theta)$ versus logarithmic of inhibitor concentration ( Log C) (Fig. 3).

\subsection{Open Circuit Potential Measurement}

Fig. (4) shows the OCP variation when $\mathrm{Al}$ electrode was exposed to aggressive $2 \mathrm{M} \mathrm{HCl}$ environment (curve A). When this experiment was carried out with $100 \mathrm{ppm} \mathrm{KIO}_{3}$ as an optimum dose, it was observed that the OCP remained almost unchanged (curve B). This observation is attributed to the presence of $\mathrm{IO}_{3}{ }^{-}$ions in $2 \mathrm{M} \mathrm{HCl}$ solution which inhibit the corrosion of the aluminum surface and enhance the growth of the pre- immersion oxide film on aluminum. 


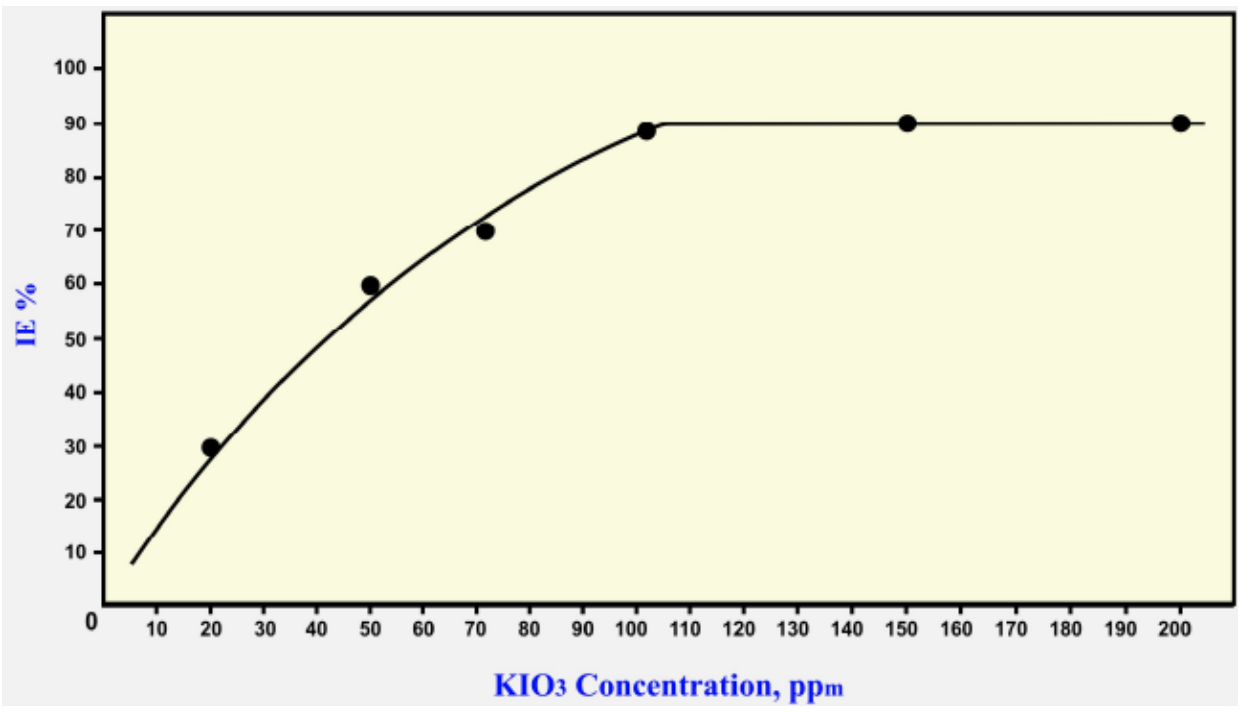

Fig. (1). Variations of the inhibition efficiency calculated from weight loss measurements at different concentrations of $\mathrm{KIO}_{3}$ in $2 \mathrm{M} \mathrm{HCl}$ at $30^{\circ} \mathrm{C}$.

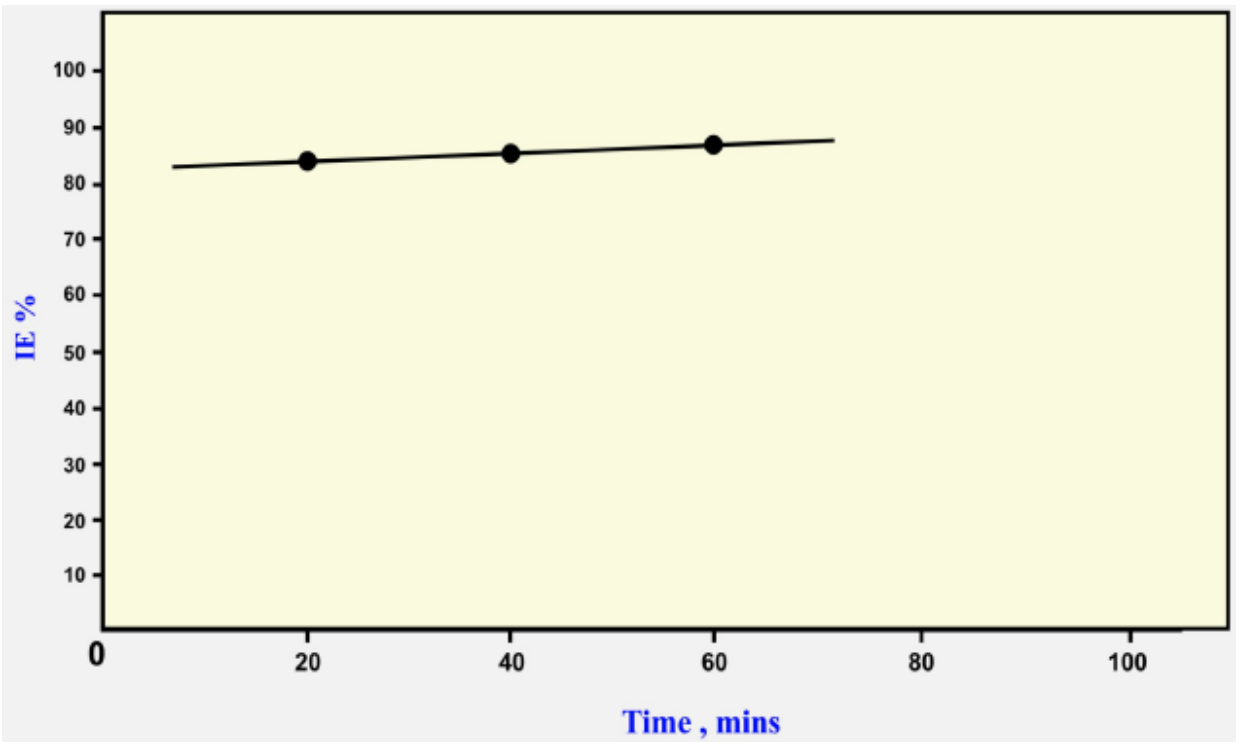

Fig. (2). Effect of immersion time on the $\mathrm{I} \mathrm{E} \%$ of $\mathrm{KIO}_{3}$ inhibitor for $\mathrm{Al}$ coupons in $2 \mathrm{M} \mathrm{HCl}$ at $30^{\circ} \mathrm{C}$.

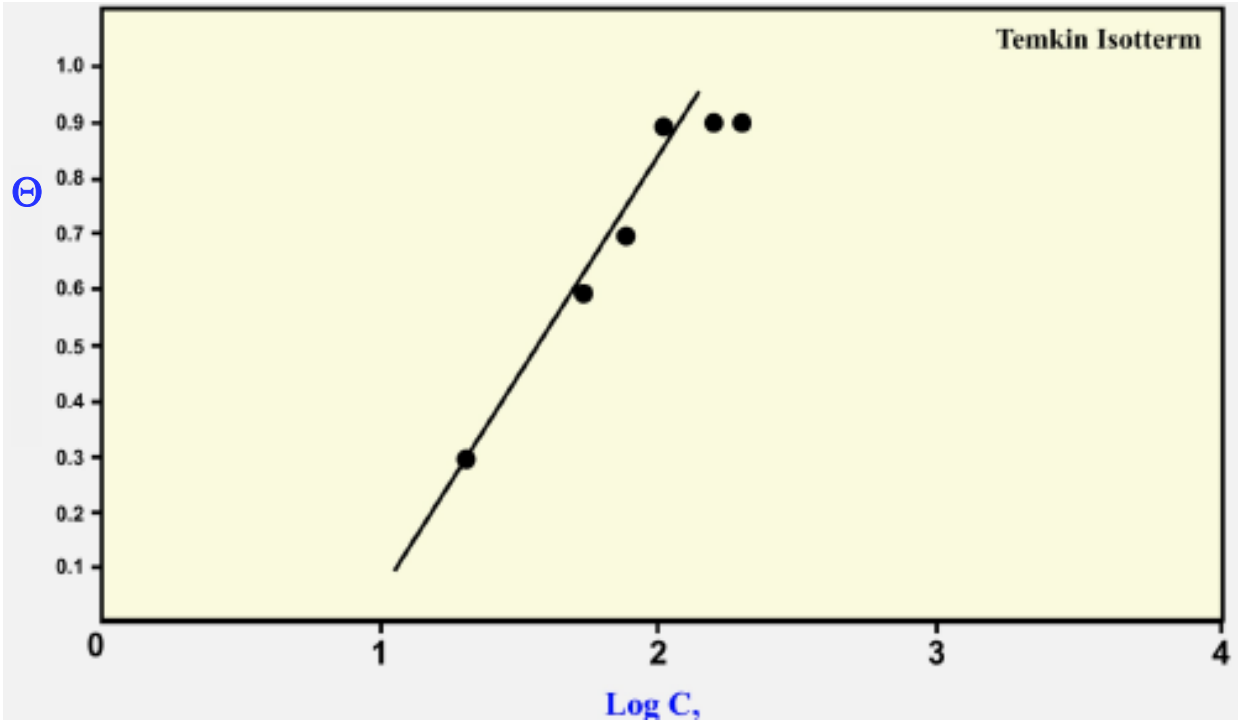

Fig. (3). Temkin adsorption plot as $\theta$ against $\log \mathrm{C}$ for $\mathrm{KIO}_{3}$ at $30^{\circ} \mathrm{C}$. 


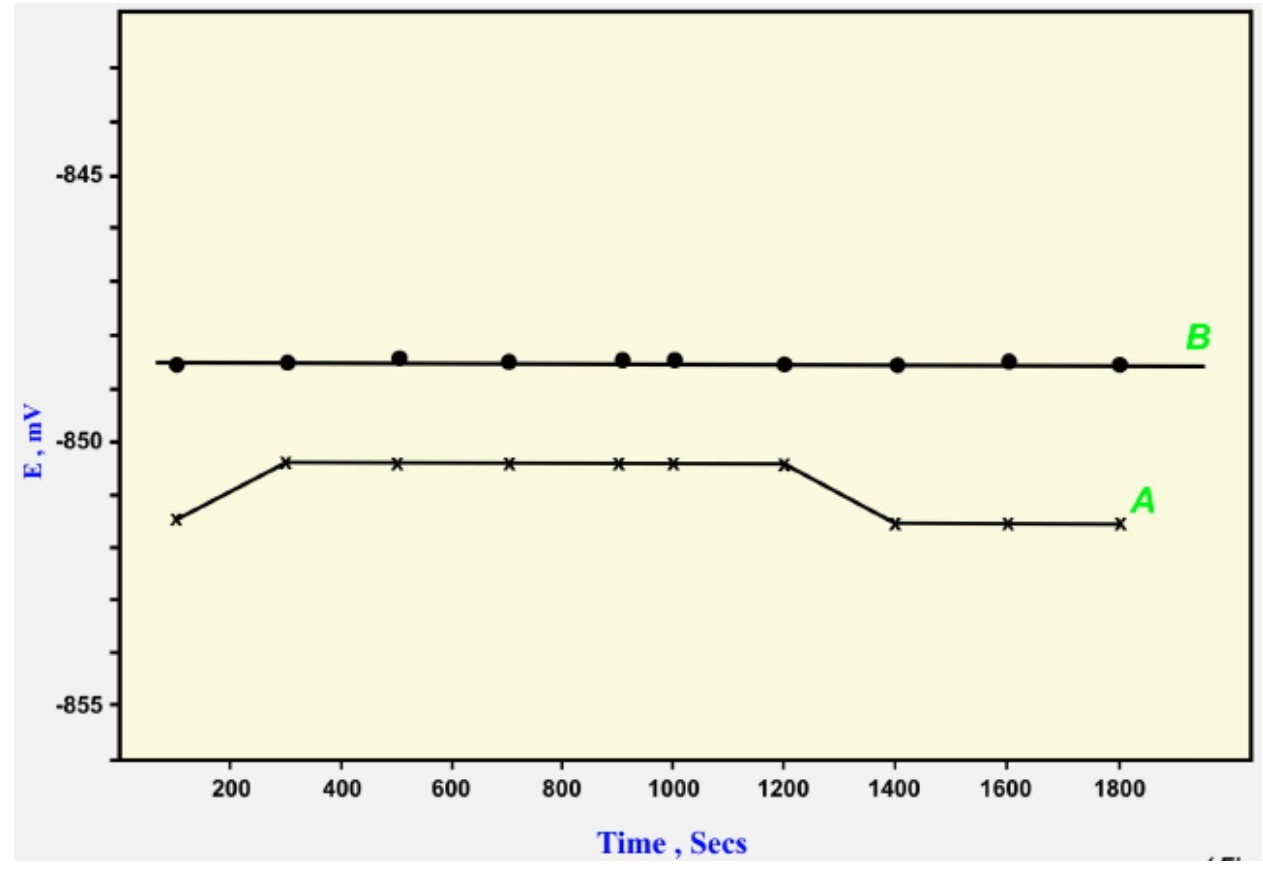

Fig. (4). Potential Vs. time plots for $\mathrm{Al}$ in $2 \mathrm{M} \mathrm{HCL}$ at $30^{\circ} \mathrm{C}$ : (A) Blank. (B) 100 ppm $\mathrm{KIO}_{3}$.

\subsection{Polarization}

Figs. $(5,6)$ represent Tafel polarization curves of aluminum in $2 \mathrm{M} \mathrm{HCl}$ in the presence of $100 \mathrm{ppm} \mathrm{KIO}_{3}$ and absence of inhibitor (blank solution). It is observed that, both of the cathodic and anodic curves show lower current density in the presence of $\mathrm{KIO}_{3}$ than recorded for the blank solution. This behavior indicated that $\mathrm{KIO}_{3}$ effects on both cathodic and anodic reactions of corrosion process. Therefore potassium iodate could be classified as mixed type (anodic/cathodic) inhibitor. The electrochemical parameters $\left(i_{\text {corr }}, E_{\text {corr }}, \beta_{\mathrm{a}}\right.$ and $\beta_{c}$ ) associated with polarization measurements and the inhibitor efficiency IE\% at $100 \mathrm{ppm}$ inhibitor concentration at $30^{\circ} \mathrm{C}$, are listed in Table 1 , where $i_{\text {corr }}, E_{\text {corr, }} \beta_{\mathrm{a}}$ and $\beta_{\mathrm{c}}$ are the corrosion current density, the corrosion potentials and anodic and cathodic Tafel slopes, respectively. Since the corrosion rate is directly related to the corrosion current density ( $\mathrm{i}_{\text {corr }}$ ), the inhibition efficiency IE\% at $100 \mathrm{ppm}$ inhibitor concentration was calculated from the equation:

IE $\%=100 \times\left(1-\frac{i_{\text {corr }}}{i_{0 \text { corr }}}\right)$

where $i_{o}$ corr and $i_{\text {corr }}$ are the corrosion current densities in the absence and presence of inhibitor. According to data

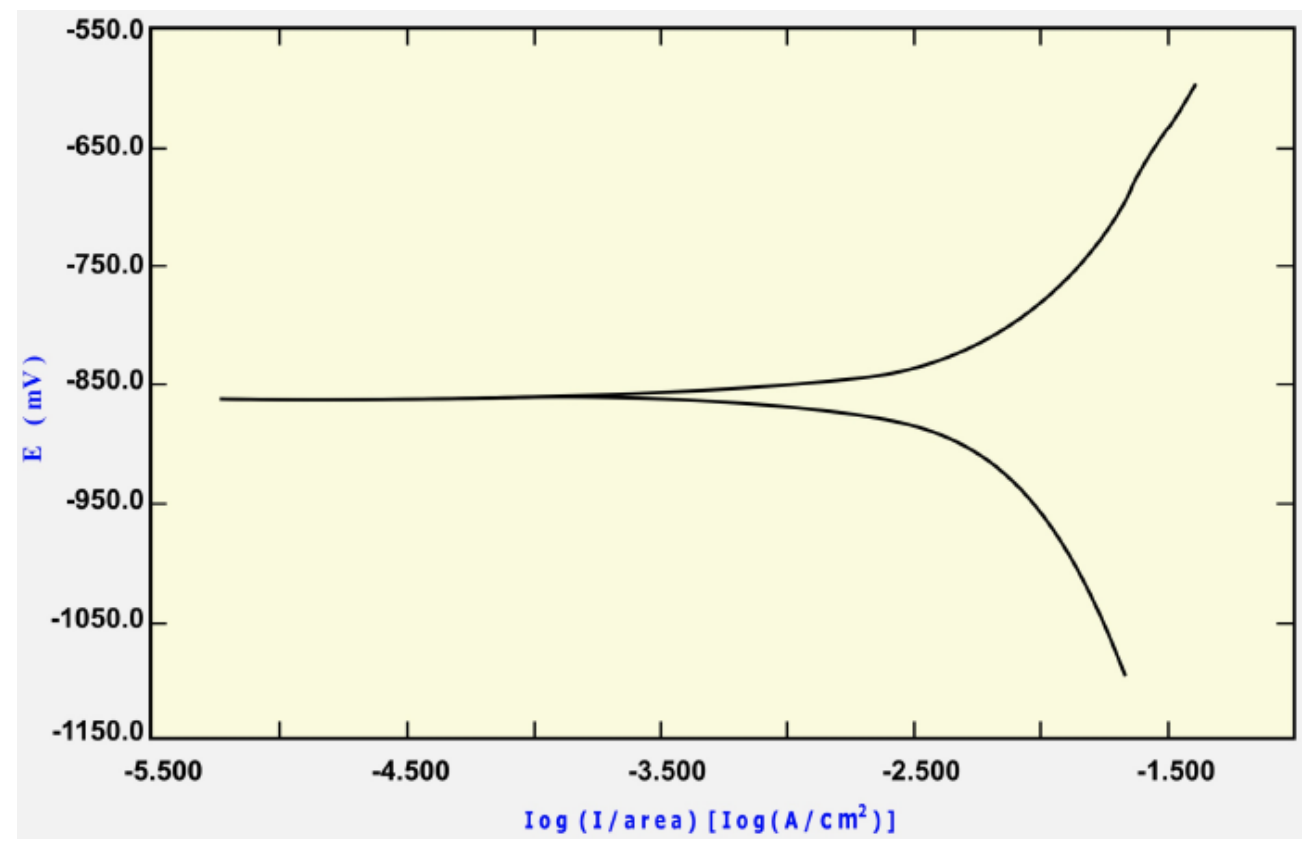

Fig. (5). Tafel polarization curve obtained for aluminum at $30^{\circ} \mathrm{C}$ in $2 \mathrm{M} \mathrm{HCl}$. 


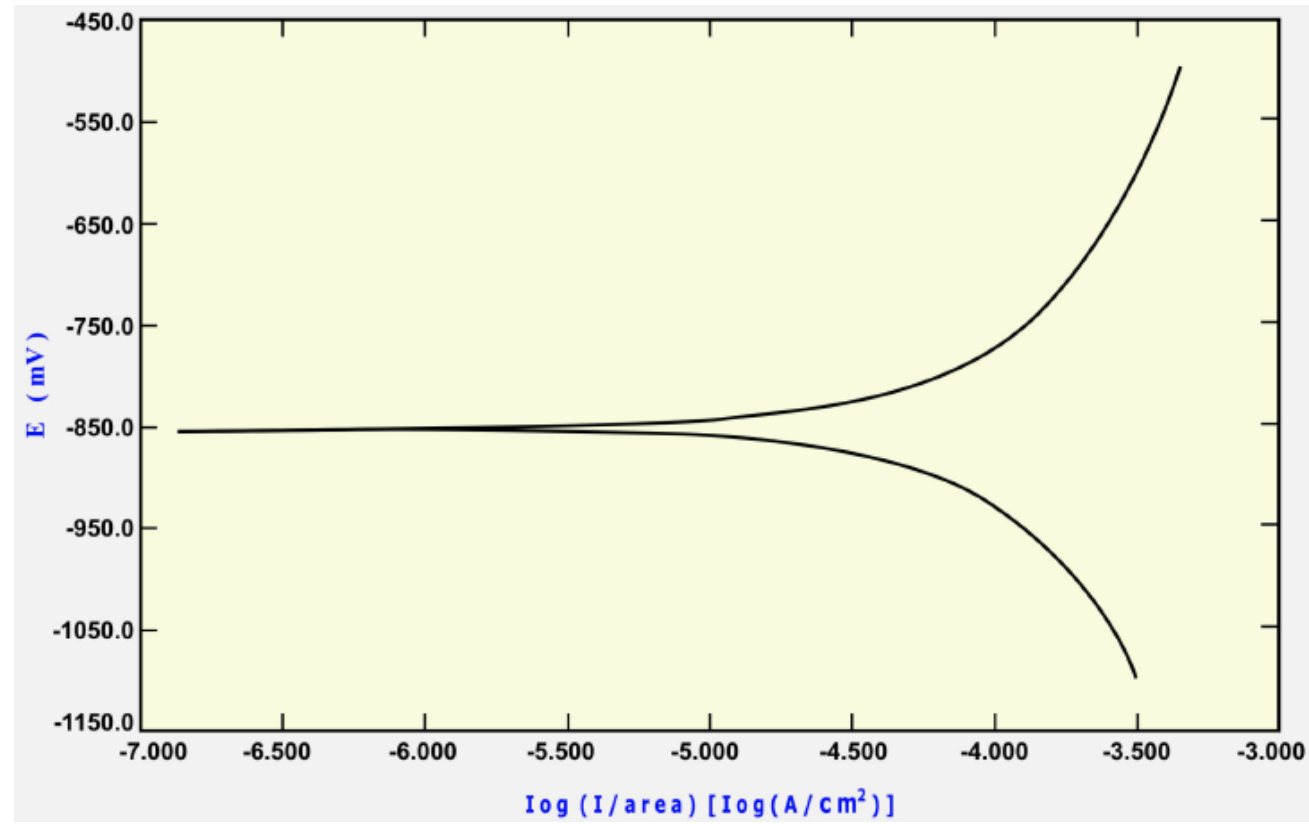

Fig. (6). Tafel polarization curve obtained for aluminum at $30^{\circ} \mathrm{C}$ in $2 \mathrm{M} \mathrm{HCl}$ containing $100 \mathrm{ppm}$ inhibitor.

obtained in Table 1, inhibition efficiency with the inhibitor was $98.63 \%$, which indicates that $\mathrm{KIO}_{3}$ compound acts as adsorption inhibitor. This idea has been examined in section 3.2; by plotting the suitable adsorption isotherm. Linear polarization measurements were conducted over the potential region, $E_{\text {corr }} \pm 20 \mathrm{mV}$ at a sweep rate of $1.66 \times 10^{-4} \mathrm{mVs}^{-1}$. Typical linear- polarization curves at room temperature $30^{\circ} \mathrm{C}$ are shown in Figs. $(\mathbf{7}, \mathbf{8})$. Polarization resistance $\left(\mathrm{R}_{\mathrm{p}}\right)$ was obtained from the slopes of such polarization curves. These data showed that as was expected, $\mathrm{R}_{\mathrm{p}}$ value was $1.072 \mathrm{~K} \Omega$ for $100 \mathrm{ppm} \mathrm{KIO}_{3}$ inhibitor. In addition, the percentage corrosion inhibition efficiency with the inhibitor was in agreement to that obtained from Tafel-line method, Table $\mathbf{1 .}$ These measurements confirmed that $\mathrm{KIO}_{3}$ is an excellent inhibitor for $\mathrm{Al}$ - corrosion in $2 \mathrm{M} \mathrm{HCl}$ at room temperature.

\subsection{Electrochemical Impedance Spectroscopy (EIS)}

Impedance measurements provide information about both the resistive and capacitive behavior of the interface and makes possible to evaluate the performance of $\mathrm{KIO}_{3}$ as possible inhibitor against aluminum corrosion. The methods for analysis of the experimental data, developed recently, enable the identification of the choice of adequate structural modes of the interface $[19,20]$. This method is widely used for investigation of the corrosion inhibition processes [21].

The effect of $100 \mathrm{ppm} \mathrm{KIO}_{3}$ concentration on the impedance behavior of $\mathrm{Al}$ in $2 \mathrm{M} \mathrm{HCL}$ solution has been studied (Fig. 9). Inspection of the data reveals that, the impedance spectra consist of a large capacitive loop at high frequencies (HFS) followed by a small inductive one at low frequency (LF) rang. The HFS capacitive loop is usually related to the charge transfer of the corrosion process and the inductive loop may be attributed to the relaxation processes in the oxide film covering electrode surface [22]. The equivalent circuit model used to fit the experimental results is given in Fig. (10) as described elsewhere [23, 24]. The frequency response analyzer is used for impedance data analysis and the fit parameters are listed in Table $\mathbf{2}$ where $R_{t}$, $\mathrm{C}_{\mathrm{dl}}$ and $\mathrm{R}_{\mathrm{s}}$ are the charge transfer resistance, double layer capacitance and solution resistance, respectively. The inhibition efficiency of 100 ppm $\mathrm{KIO}_{3}$ concentration was calculated from the following equation:

$\mathrm{IE} \%=\left(1-\frac{\mathrm{C}_{\mathrm{dl}}}{\mathrm{C}_{\mathrm{dl}}^{\circ}}\right)$

where $\mathrm{C}_{\mathrm{dl}}^{\circ}$ and $\mathrm{C}_{\mathrm{dl}}$ are the double layer capacitance of the electrode without and with the inhibitor, respectively. Inspection of Table 2 reveals that $\mathrm{R}_{\mathrm{t}}$ value will be higher in presence of $100 \mathrm{ppm} \mathrm{KIO}_{3}$, and lower with respect to $\mathrm{C}_{\mathrm{dl}}$. This is due to surface coverage by the inhibitor, which leads to higher IE\%. The electrochemical theory shows that $\mathrm{C}_{\mathrm{dl}}$ is proportional to the corrosion rate [24]. From the resistance $R_{t}$ that represnts the corrosion process, the surface coverage may be calculated as follows,

$$
\overline{\mathrm{R}_{\mathrm{t}}(0)}=\frac{162.3}{\mathrm{R}_{\mathrm{t}}(100)}=\frac{1 / \mathrm{S}(0)}{1 / \mathrm{S}(100)}
$$

where $\mathrm{S}$ is the area of surface on which no inhibitor adsorbs.

$$
\begin{aligned}
& \frac{S(100)}{S(0)}=\frac{162.3}{1310} \\
& \Theta=\frac{S(0)-S(100)}{S(0)}=\frac{1310-162.3}{1310}=0.876
\end{aligned}
$$

The polarization resistance calculated from polarization Table $\mathbf{1}$ and impedance technique Table $\mathbf{2}$, was found to increase in presence of iodate ion. This means that EIS measurements are in good agreement with polarization measurements. 
Table 1. Electrochemical Parameters of Corrosion of $\mathrm{Al}$ in $2 \mathrm{M} \mathrm{HCL}$ at $30^{\circ} \mathrm{C}$ without and with $100 \mathrm{ppm} \mathrm{KIO}_{3}$ and $\mathrm{Corresponding}$ Inhibition Efficiencies Obtained from Polarization Method

\begin{tabular}{|c|c|c|c|c|c|c|c|}
\hline & $\mathbf{E}_{\text {corr }}(\mathbf{m V})$ & $\boldsymbol{\beta a}(\mathbf{V} / \mathbf{d e c})$ & $\boldsymbol{\beta}_{\mathbf{c}}(\mathbf{V} / \mathbf{d e c})$ & $\left.\mathbf{R}_{\mathbf{p}}(\mathbf{\Omega c m})^{-2}\right)$ & $\mathbf{i}_{\text {corr }}$ & $\mathbf{C .} \mathbf{R .}$ & $\mathbf{I E} \%$ \\
\hline \hline Blank & -862.5 & $333.5 \times 10^{-3}$ & $372.6 \times 10^{-3}$ & 4.7 & $5.547 \mathrm{~mA} / \mathrm{cm}^{2}$ & $7.138 \times 10^{3} \mathrm{mpy}$ & --- \\
\hline $\begin{array}{c}100 \mathrm{ppm} \\
\mathrm{KIO}_{3}\end{array}$ & -853.7 & $386 \times 10^{-3}$ & $381 \times 10^{-3}$ & 1072 & $75.68 \mu \mathrm{A} / \mathrm{cm}^{2}$ & $97.38 \mathrm{mpy}$ & $98.63 \%$ \\
\hline
\end{tabular}

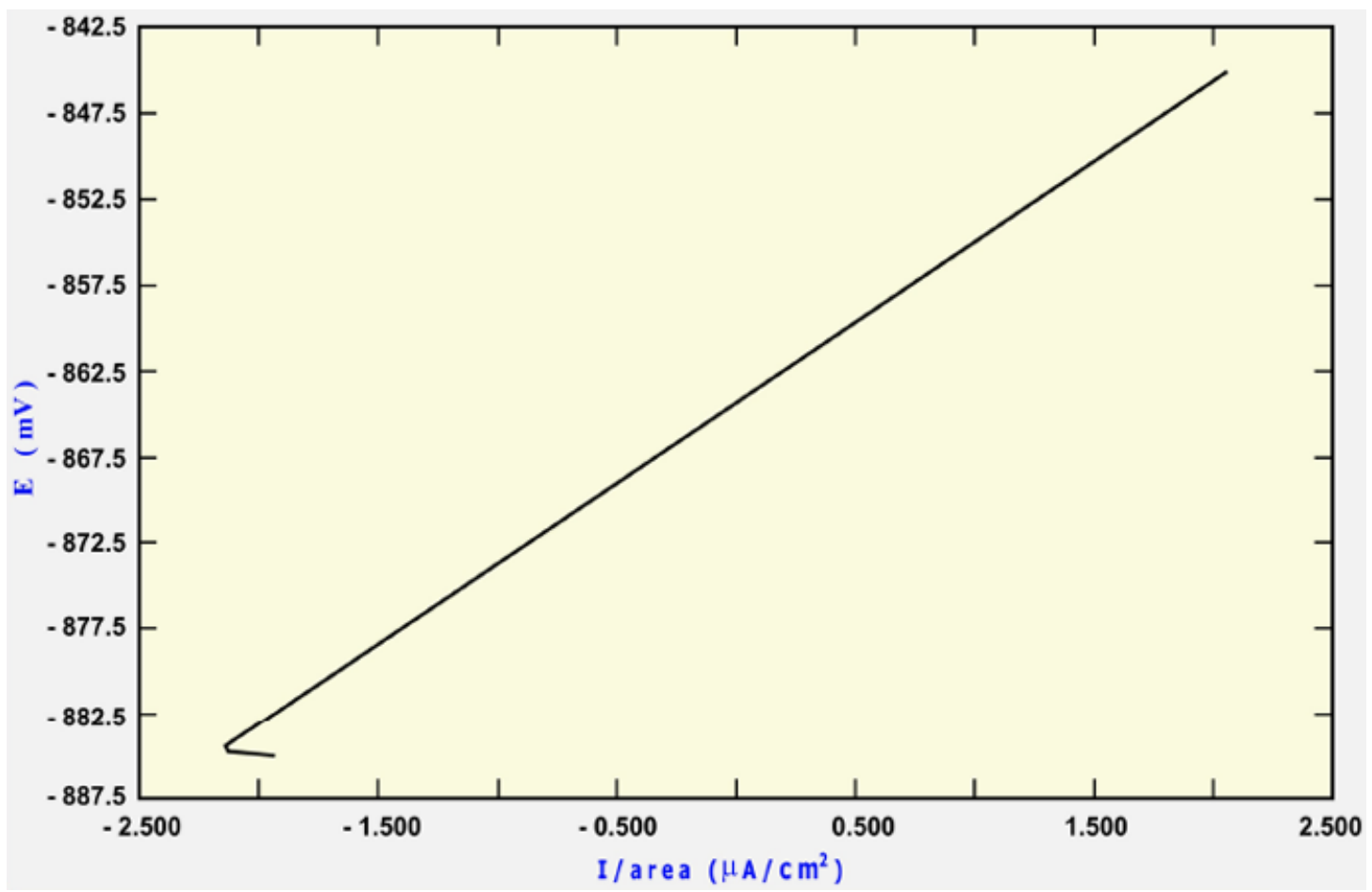

Fig. (7). Polarization resistance measurement for $\mathrm{Al}$ in $2 \mathrm{M} \mathrm{HCl}$ at $30^{\circ} \mathrm{C}$.

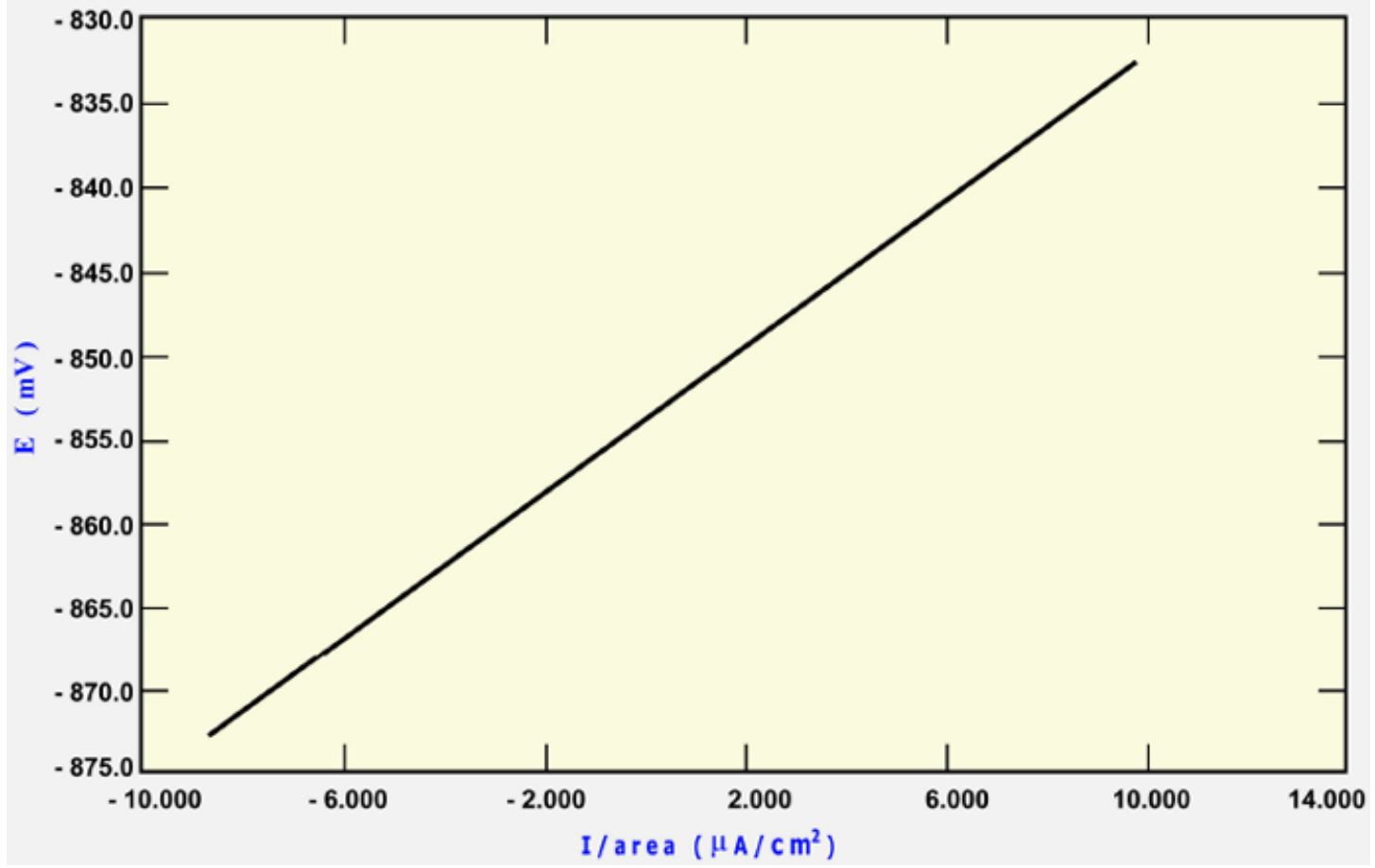

Fig. (8). Polarization resistance measurement for $\mathrm{Al}$ in $2 \mathrm{M} \mathrm{HCl}$ at $30^{\circ} \mathrm{C}$ containing $100 \mathrm{ppm} \mathrm{KIO}_{3}$. 
Table 2. Impedance Parameters and Corresponding Inhibition Efficiency for the Corrosion of Aluminum in $2 \mathrm{M} \mathrm{HCl}$

\begin{tabular}{|c|c|c|c|c|c|}
\hline & $\mathbf{C}_{\text {inh. }}$ & $\mathbf{R}_{\mathbf{s}}\left(\mathbf{\Omega c m}^{-2}\right)$ & $\mathbf{R}_{\mathbf{t}}\left(\mathbf{\Omega c m}^{-2}\right)$ & $\mathbf{C}_{\mathrm{dl}}(\boldsymbol{\mu} \mathbf{F})$ & $\mathbf{I E} \%$ \\
\hline \hline Blank & ---- & 1.6 & 162.3 & 25.83 & --- \\
\hline $\mathrm{KIO}_{3}$ & $100 \mathrm{ppm}$ & 3.21 & 1310 & 1.04 & 96.34 \\
\hline
\end{tabular}

\section{CONCLUSION}

Chemical and electrochemical measurements were used to study the corrosion inhibition of $\mathrm{Al}$ in $2 \mathrm{M} \mathrm{HCl}$ solution at the corrosion potential using potassium iodate as corrosion inhibitor. The principle conclusions are:
1) $\mathrm{KIO}_{3}$ was found to be effective inhibitor for aluminum in $2 \mathrm{M} \mathrm{HCl}$ solution.

2) The corrosion process is inhibited by the adsorption of its molecules on aluminum surface.

3) Double layer capacitance decreases with respect to the blank solution when the inhibitor is added; this fact may be explained on the basis of adsorption of $\mathrm{KIO}_{3}$ on the aluminum surface.

4) In determining the corrosion rates, electrochemical studies and weight loss measurements are coincide.

5) The data obtained from weight loss technique fit well the Temkin adsorption isotherm.

6) The corrosion inhibition efficiency of iodate anion was found to be $90 \%$ by weight loss, $98 \%$ by Tafel polarization and $96 \%$ by EIS measurements.

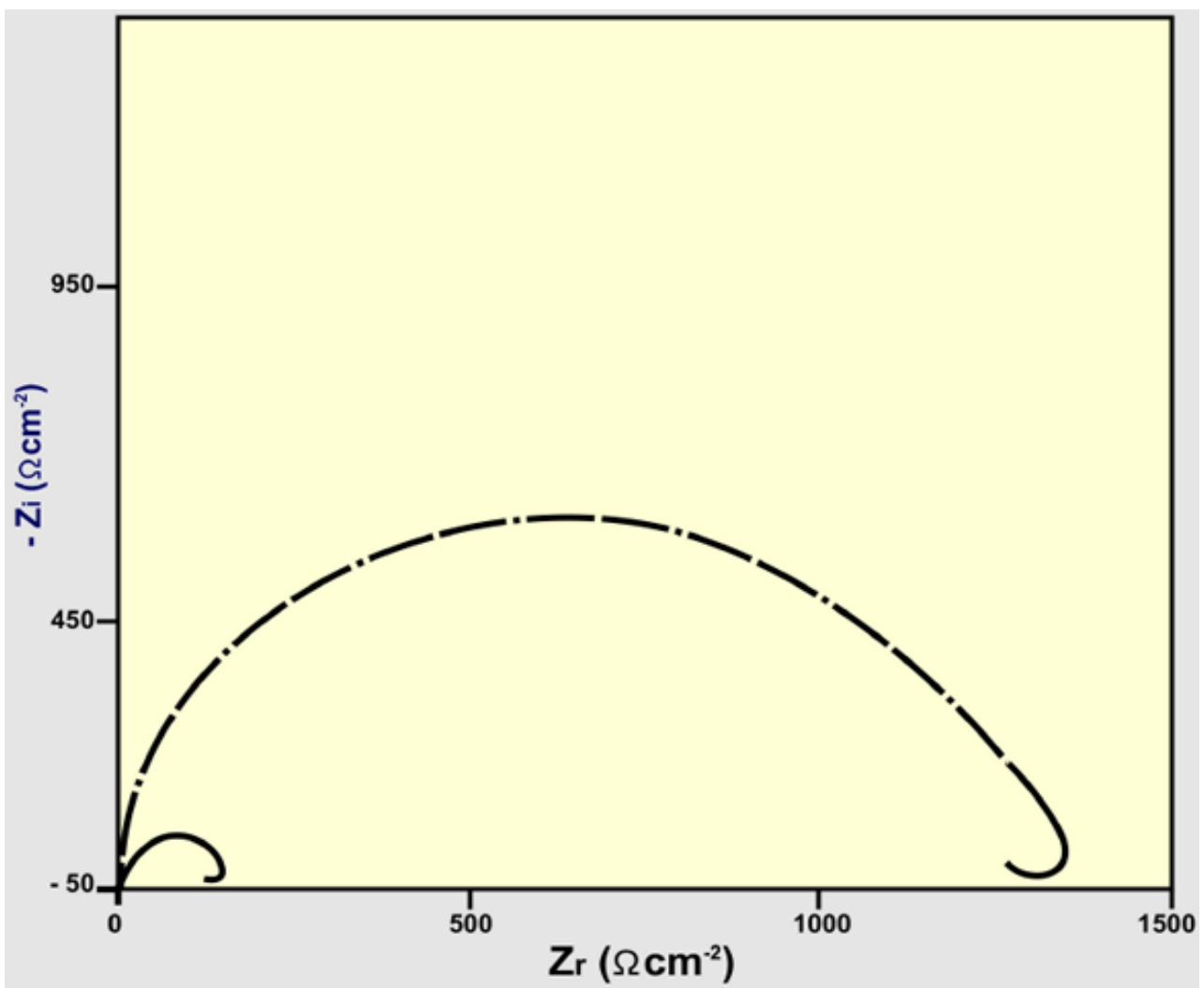

Fig. (9). Impedance plot obtained at $30^{\circ} \mathrm{C}$ for $\mathrm{Al}$ in $2 \mathrm{M} \mathrm{HCl}$ containing $100 \mathrm{ppm} \mathrm{KIO}_{3}$ inhibitor.

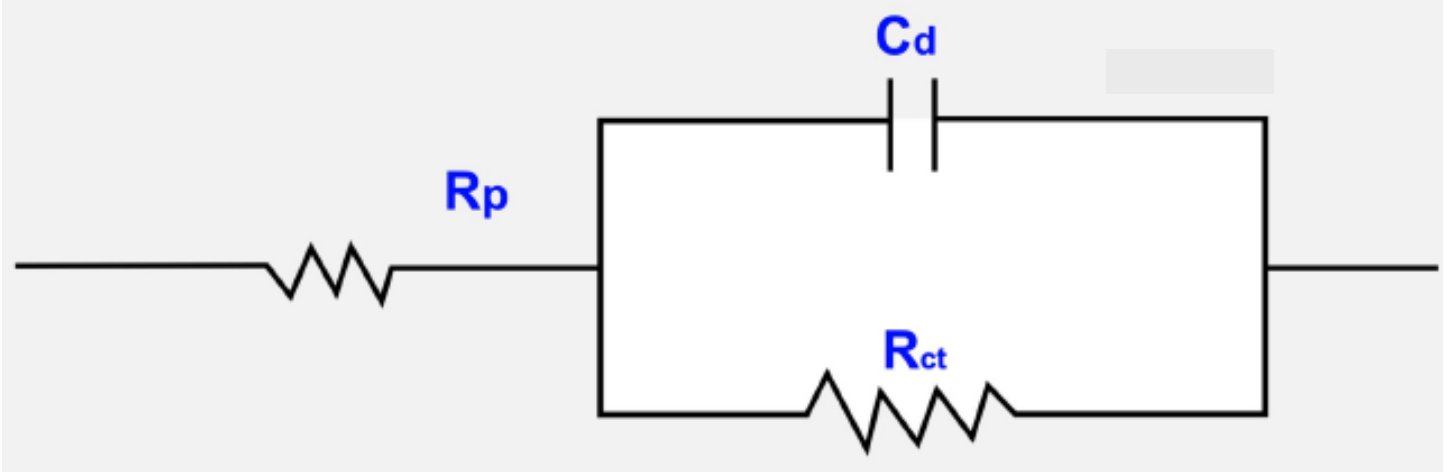

Fig. (10). The equivalent circuit model used to fit the experimental results. 


\section{REFERENCES}

[1] Ergun U, Yuzer D, Emregul KC. The inhibitory effect of bis-2, 6(3, 5-dimethylpyrazolyl) pyridine on the corrosion behaviour of mild steel in HClsolution. Mater Chem Phys 2008; 109: 492-9.

[2] Hurlen T, Lian HH, Odegard OS, Valand TV. Corrosion and passive behaviour of aluminium in weakly acid solution. Electrochim Acta 1984; 29: 579-85.

[3] El-Etre AY. Inhibition of aluminum corrosion using opuntia extract. Corrosion Sci 2003; 45: 2485-95.

[4] Pourbaix M. Atlas of electrochemical equilibriua in aqueous solutions. New York: Pergamon Press 1966.

[5] Abdullah M. Antibacterial drugs as corrosion inhibition for corrosion of aluminum in hydrochloric acid solution. Corrosion Sci 2004; 46: 1981-96.

[6] Luo Q. Copper dissolution behavior in acidic iodate solutions. Langmuir 2000; $16: 5154-8$

[7] Mogoda A, Ahmead Y, Badawy W. Corrosion inhibition of Ti-6Al$4 \mathrm{~V}$ alloy in sulfuric and hydrochloric acid solutions using inorganic passivators. Mater Corrosion 2004; 55: 449-56.

[8] Toraishi T, Nagaski S, Tanaka S. In: Tokyo Daigaku Genshiryoku Kenkyo Sogo Senta Shin Ponjumu, 1999, 8th, 1999; p. 152.

[9] Azim SS, Muralidharan S, Iyer SV, Muralidharan B, Vasudhevan T. Synergistic influence of iodide ions in inhibition of corrosion of mild steel in $\mathrm{H}_{2} \mathrm{SO}_{4}$ by N-Phynylthiourea. Br Corrosion J 1998; 33: 297-301.

[10] Feng Y, Siow KS, Teo WK, Hsieh AK. The synergistic effects of propargyl alchol and potassium iodide on the inhibition of mild steel in 0.5M sulfuric acid solution. Corrosion Sci 1999; 41: 82952.

[11] Quraishi MA, Rawat I, Ajmal M. Synergistic effect of iodide ions on inhibitive performance of substituted dithiobiurets during corrosion of mild steel in hot hydrochloric acid. Corrosion (Houston) 1999; 55: 919-23.
[12] Oguzie EE, Unaegbu C, Okolue CN, Onuchukwu AI. Inhibition of mild steel corrosion in sulfuric acid using indigo dye and synergistic halide additives. Mater Chem Phys 2004; 84: 363-8.

[13] Oguzie EE. Influence of halide ions on the inhibitive effect of congo red dye on the corrosion of mild steel in sulfuric acid solution. Mater Chem Phys 2004; 87: 212-7.

[14] Umoren SA, Obot IB, Akpabia LE, Etuk SE. Adsorption and corrosive inhibitive properties of viga unguiculate in alkaline and acidic media. Pigment Resin Technol 2008; 37: 98-106.

[15] Khaled KF. New synthesized guanidine derivative as a green corrosion for mild steel in acidic solutions. Int J Electrochem Sci 2008; 3: 462-75.

[16] Khaled KF. Molecular simulation, quantum chemical calculations and electrochemical studies for inhibition of mild steel by triazoles. Electrochim Acta 2008; 53: 3484-92.

[17] Kendig M, Jeanjaquet S. Cr (VI) and CE (III) inhibition of oxygen reduction on copper. J Electrochem Soc 2002; 149: B47-B51.

[18] Hosseini MG, Mertens SFL, Gorbani M, Arshadi MR. Assymmetrical Schiff bases as inhibitiors of mild steel corrosion in sulphoric acid media. Mater Chem Phys 2003; 78: 800-8.

[19] Stoynov ZB, Grafov BM, Savova-Stoynova B, Elkin VV. Electrochemical impedance. Moscow: Nauka 1991.

[20] Gabrielli G. Identification of electrochemical processes by frequency response analysis. Technical Report 004/83, 1984; 120.

[21] Lopez DA, Simison SN, de Sanchez SR. The influence of steel microstructure on corrosion. EIS Studies on the inhibition efficiency of benzimidazole. Electrochim Acta 2003; 48: 845-54.

[22] Abd El-Rehim SS, Hassan HH, Amin MA. Corrosion inhibition of aluminum by 1,1 (Lauryl amido) propyl ammonium chloride in $\mathrm{HCl}$ solution. Mater Chem Phys 2001; 70: 64-72.

[23] Sekine I, Satongi M, Hagiuda H, et al. Corrosion inhibition of steel by cationic and anionic polymers in cooling water system. J Electrochem Soc 1992; 139: 3167-73.

[24] Lorenz WJ, Masfeld F. Determination of corrosion rates by electrochemical DC and AC methods. Corrosion Sci 1981; 21: 64772.

(C) A.A. El Maghraby; Licensee Bentham Open.

This is an open access article licensed under the terms of the Creative Commons Attribution Non-Commercial License (http://creativecommons.org/licenses/by$\mathrm{nc} / 3.0 /$ ) which permits unrestricted, non-commercial use, distribution and reproduction in any medium, provided the work is properly cited. 